\title{
Studies on Electrostatic Charging in the Printing Process in High-Speed Rotary Photogravure
}

Eschenbach, W.; Fritsch, K.

(1967)

DOI (TUprints):

License:

Publication type:

Division:

Original source: https://doi.org/10.12921/tuprints-00013978

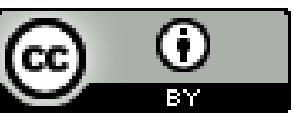

CC-BY 4.0 International - Creative Commons, Attribution Article

16 Department of Mechanical Engineering

16 Department of Mechanical Engineering

https://tuprints.ulb.tu-darmstadt.de/13978 
Sonderdruck aus:

Advances in Printing Science and Technology

Volume 4

Pergamon Press · Oxford \& New York · 1967

Studies on Electrostatic Charging in the Printing Process in High-Speed Rotary Photogravure

by W. Eschenbach and K. Fritsch

Vortrag, gehalten auf der Eight International Conference of Printing Research Institutes in Helsinki am 18. Juni 1965

Institut für Druckmaschinen und Druckverfahren der Technischen Hochschule Darmstadt Institutsdirektor: o. Prof. Dipl.-Ing. Karl R. Scheuter 


\title{
STUDIES ON ELECTROSTATIC CHARGING IN THE PRINTING PROCESS IN HIGH-SPEED ROTARY PHOTOGRAVURE
}

\author{
by W. EsChenbach and K. FritsCH \\ Institut für Druckmaschinen und Druckverfahren der Technischen Hochschule, \\ Darmstadt
}

THE problems posed by electrostatic charges in printing machines have increasingly gained importance in recent years.

This paper is intended to guide the designer of printing machines in the matter of suitable measures for minimizing static generation.

Questions relating to the removal of the charge through the use of dischargers or of increasing the conductivity of a paper by chemical means either during the production process or subsequent surface treatment have not been given consideration. Suffice it to say, that Macourek(1), in 1964 prepared an excellent summary of internationally available electrostatic dischargers, classifying them in groups according to their method of operation. Attempts to reduce the tendency of a paper to build up a charge by adding certain substances to the paper stock ${ }^{(2-5)}$ are somewhat older. Clearly, the difficulty here is that in producing a paper emphasis is laid first and foremost on an optimum printability, but at the same time economic considerations can never be neglected. Furthermore, plastic films are being used increasingly as printing materials. The goal of the subsequent surface treatment with antistatic agents is to reduce friction, and hence the contact potential, between the surfaces in contact. Higher alcohols, owing to their hygroscopic nature, affect the conductivity. Surface-active agents also serve to reduce the contact potential.

By way of introduction, let us briefly review the mechanism of electrostatic charge build up and the physical laws which apply. During its run through the printing press the printing medium (paper) comes into contact with widely different materials, such as metals, rubber, printing inks, high polymers and paper. In this way, the paper experiences everything from 
lightly touching contact to deformation, heating and eventually friction with paper or other materials and is subjected to the most complex combination of stresses. Theoretically, the formation of an electrostatic charge could equally well be a result of the piezo or the pyroelectric effect, as well as of contact. As a result of various experiments ${ }^{(6)}$ the electrostatic charge, resulting from the piezo and pyroelectric effect, may be considered negligible.

The following, therefore, is based on the two main sources of electrostatic charge in paper: contact and friction. Generally, the surfaces of previously uncharged materials carry a charge after having been in intimate contact. Hence, it is possible to classify the materials in a potential series (Fig. 1). According to the Cöhn Rule:(7)

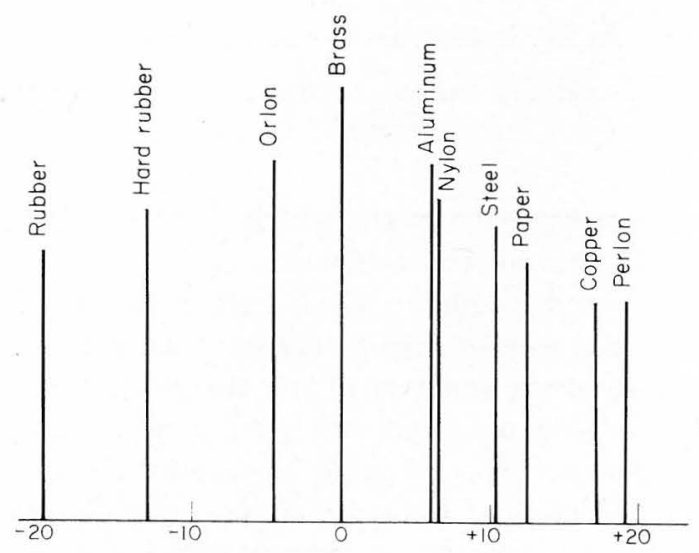

Fig. I. Electrostatic potential series.

1. The dielectric with the larger dielectric constant (DK) becomes positively charged with respect to the dielectric with the smaller DK.

A larger DK also corresponds to a greater displacement of the charge within the molecules.

2. The charge produced, when two dielectric bodies in contact are separated is proportional to the difference in the (DK) of the two dielectric materials. If the DK's are $\epsilon_{1}$ and $\epsilon_{2}$

$$
Q=K /\left(\epsilon_{1}-\epsilon_{2}\right) .
$$

Experiments investigating the effect of the ambient air on the build-up of electrostatic charge are presently being carried out in our Institute. It is well known that at higher humidity, the electrostatic charge developed in printing plants is lower. To what extent this is actually due to lower formation or to a better discharge and to what degree it is affected by the ambient 
air or by the paper is at present being examined. At present reference will only be made to the paper. $(6,7,9)$

Two media in contact form electrical double layers at their common surface. This can be explained by the presence of an inwardly directed electric field, which effects a polarization. Whereas Helmholtz regarded the exchange of charge as due to electrons only and not to ions, Böning (10-12) and Grüner(6) advanced the theory that, especially by insulators, an exchange of ions is possible. This view has been supported by their experimental results. Böning found in the surface of various materials adsorbed fixed "boundary-layer-ions" which are different in charge and mobility. These boundary-layer-ions are surrounded by mobile "complementary-ions", which when removed cause the materials to carry a charge. In addition to the above explanations for two lightly touching materials, Grüner defines the so called "area effect", which takes place when two unequally large areas are rubbed together. Generally speaking heat produced by friction increases ion mobility. Thus ions pass from the smaller to the larger surface, and a charge is formed.

In the last analysis, the mechanism of the exchange of charge at the boundary layer is still largely obscure. However, many phenomena can be explained with Böning's theory. Furthermore, the so-called "area-effect", according to Grüner, affords an explanation for the formation of electrostatic charge on two materials having the same electrostatic properties, when undergoing friction.

\section{MEASURING INSTRUMENTS AND METHODS}

Electrostatic field density-meters (system Schwenkhagen) were used in making the measurements. These field density-meters employ the induction

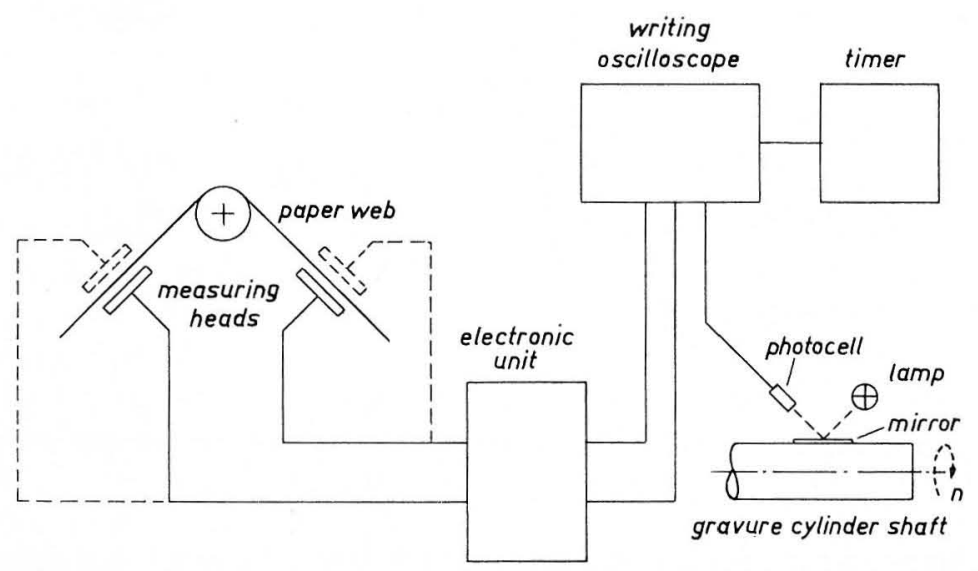

Fig. 2. Schematic diagram of measuring apparatus. 
principle for producing a measuring current from the mechanical motive energy of a separately excited generator. The field to be measured serves as the exciter field. No energy is removed from it during the entire measurement as the motor and amplifier supply all the power required by the indicator.

Furthermore, a capacitive measuring probe with built-in electrometer amplifiers was used.

Measuring instruments which operate using radioactive elements were not employed in these experiments because of their lower accuracy.

A charge is measured by measuring the force with which it is attracted or repelled by another charge.

$$
\text { where } \begin{aligned}
K & =\text { force }(\mathrm{N}), \\
\epsilon & =\mathrm{DK} \text { of the special dielectricum, } \\
\epsilon_{0} & =\text { the dielectric constant of a vacuum, } \\
& =8.859 \cdot 10^{-12}(\mathrm{~A} \cdot \mathrm{sec} / \mathrm{V} \cdot \mathrm{m}), \\
Q_{1}, Q_{2} & =\text { charge }(\mathrm{Coul}), \\
r & =\text { distance }(\mathrm{m}) .
\end{aligned}
$$

The charge density is defined as the charge/area

where $E=$ field density $(\mathrm{V} / \mathrm{m})$

$$
\sigma=E \cdot \epsilon\left(\text { in Coul. } / \mathrm{m}^{2}\right)
$$

$\epsilon=$ the dielectric constant of the medium (A . sec/V . m).

In a plate condenser the electric field density is:

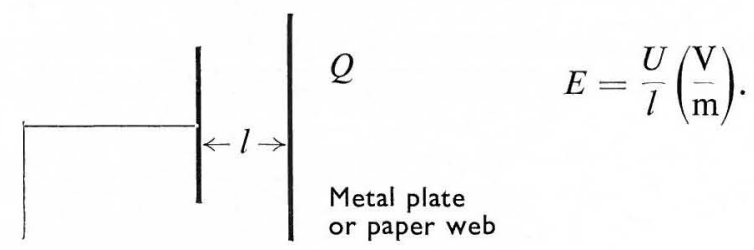

In a homogeneous field the charge is directly proportional to the field density. If the gap, $l$, is changed at constant charge, $E$ remains constant.

$$
Q=C \cdot U
$$

where: $Q=$ charge (Coul.),

$C=$ capacity $(\mathrm{F})$

$U=\operatorname{potential}(\mathrm{V})$.

By substituting $U=E \cdot l$ and $C=$ const. $1 / l$ in the above, we get

$$
Q=\text { const. } \cdot E
$$

for a homogeneous field. However, it should be remembered that even on a freely suspended paper web we have to deal with a more or less non-uniform 
field. In addition, foreign electric fields are usually present near machine parts and other objects. More often than not these cause a distortion of the field. The non-uniformity of the electric field is a function of:

1. The distribution of charge on the paper surface.

2. The presence of stray and foreign fields as well as distortion arising from the geometry of the surroundings.

3. The modus operandi of the measuring apparatus used.

\section{MEASUREMENTS OF THE PAPER WEB OF DIFFERENT- SIZED ROTARY PHOTOGRAVURE MACHINES}

The curves depicted in Fig. 3 were recorded after the fifth printing unit

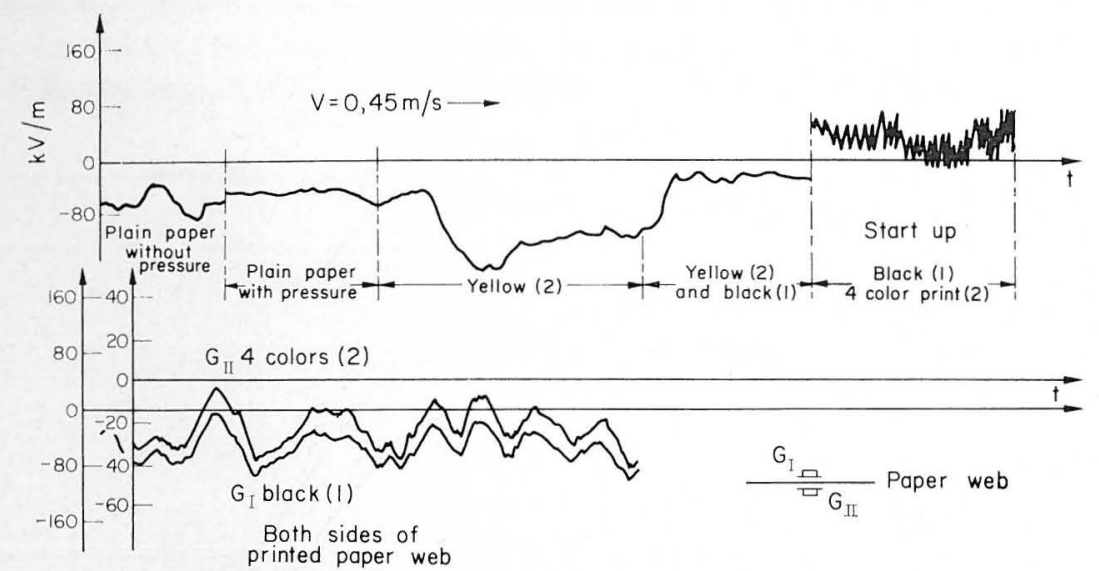

Fig. 3. The influence of the amount and distribution of printing ink of the electrostatic charge on the paper web.

and a few guide rollers before the cross cutter and folding unit. In the upper curve, the following were successively recorded: strong fluctuations in the charge build-up prior to printing, smoothing out at the moment of printing of the first printing unit (we shall come back to this later), steep rise of the already negatively charged second-print (yellow) on the reverse side of the paper, drop-off during first printing (black) and, finally, the characteristic charge behaviour after the completed one-color recto and four-color verso print. During the entire measuring sequence the press ran at a web feeding speed of $0.45 \mathrm{~m} / \mathrm{sec}$.

The lower curves showing the field density were recorded using two measuring heads, one on the first side and the other on the reverse side, mounted directly above an almost full-tone area. They show a continuous uniform change in the average value of the charge on both sides of the paper 
web, as well as a change in polarity, but primarily a negative charge. As we shall see this is a typical charging characteristic of both sides of a printed paper web. The electrostatic charges on the upper and lower sides of the paper web are interdependent. The charge measured with measuring head $\overline{\mathrm{G}}$ II (Fig. 3) on the reverse side does not at all appear to be influenced by the guide roller approx. $40 \mathrm{~cm}$ distant, owing to the high operating speed $(v=5.4 \mathrm{~m} / \mathrm{sec})$. Both measurements were taken at $22.4^{\circ} \mathrm{C}$ and 40 per cent r.h.

From the curves (Fig. 3), the influence of the ink on the charge build-up is clear. Prof. Flegler, in his experiments on the conductivity of gravure printing inks, found a dependence on the composition as summarized in Fig. 4.

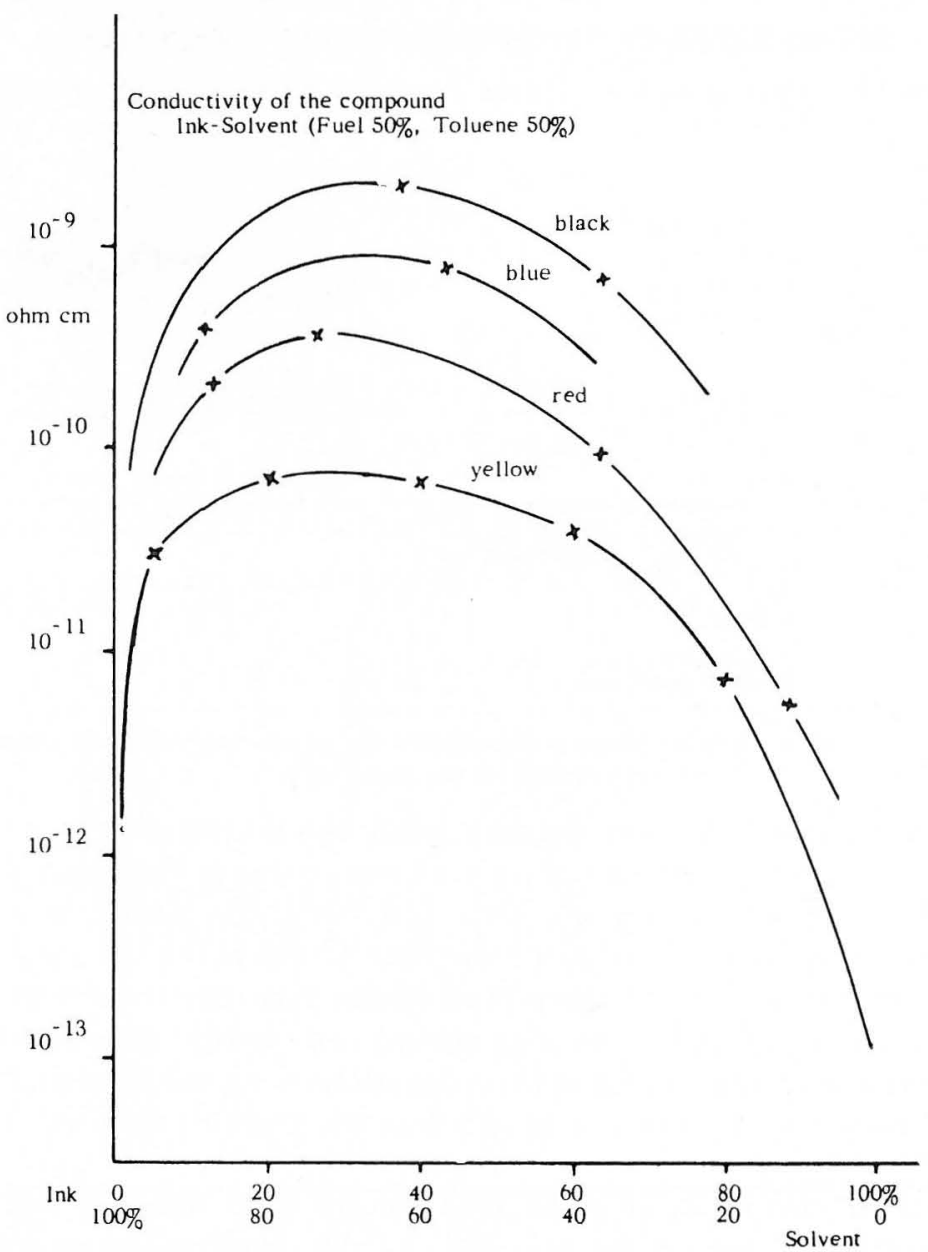

Fig. 4. Conductivity of gravure printing inks as a function of their consistency according to Prof. Flegler. (13) 
Whereas, the fluctuations of charge are small on plain paper, they may, in some cases, be very large on printed paper webs. The size of the charge may vary depending on the tonal value and number of superimposed prints.

The curves depicted in Fig. 3 were supported by repeated measurements on a number of presses, thereby confirming the influence of the ink on the charge. Measurements in other zones across the breadth of the cylinder gave different, but in principle similar, results. The beginning of the first reverse printing stage (yellow) is not always noticeable on the first printing side. This may best be explained by the change in the amount and distribution of the printing ink used. The start of recto printing always causes a drop in the negative electrostatic charge and the remaining three reverse printing units (red, blue, black) lead to large fluctuations in charge. These fluctuations were repeatedly found to parallel the speed of rotation of the gravure cylinder.

In order to understand the role of the individual parameters, the influence of the pasting process in an Autopaster (a two-roll Autopaster System HUCK)
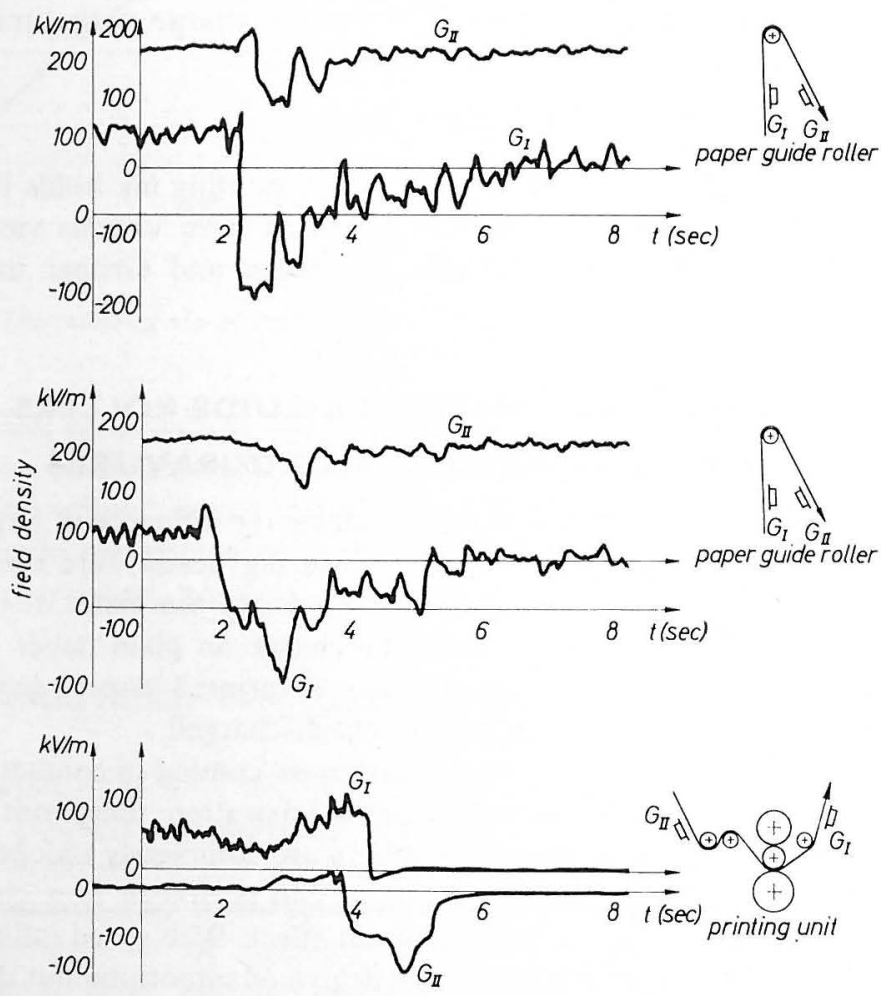

Fig. 5. The electrostatic behaviour during the automatic pasting operation at $v_{\text {paper }} \approx 5.4 \mathrm{~m} / \mathrm{sec}$. 
on the charge was measured behind several paper guide rollers and printing units. The web speed during the pasting process was always maintained at $5.3-5.4 \mathrm{~m} / \mathrm{sec}$. The characteristic curves obtained are shown in Fig. 5. In all three cases, a noticeable negative charge is formed at the moment of pasting. These typical fluctuations in the charge occurring during pasting decrease with increasing distance from the "Autopaster".

If we regard the paper as experiencing a momentary stress impulse, this behaviour can be explained by the "area effect" theory. Any influence exerted by a 0.5 to $1.5 \mathrm{~m}$ long pasted-overlap is indirect (see Fig. 11).

Any variation in the average value of the charge can be related to the condition of the new paper roll. The electrostatic behaviour of the three curves after the pasting process cannot be generalized.

The influence of the printing ink was characterized by measuring the time required to discharge a charged paper web when a press operating at $V_{\mathrm{cyl}}=$ 18,000 r.p.h. $\left(v_{\text {web }}=5.3 \mathrm{~m} / \mathrm{sec}\right)$ was suddenly stopped. The time required from the moment of stoppage was: approx. $6 \mathrm{sec}$ for plain papers and approx. $50 \mathrm{sec}$. for printed papers. The loss of charge with time was in every case exponential where the time constants

$$
T_{\text {printed }}>T_{\text {plain }}
$$

This plainly illustrates that a paper wetted with printing ink holds its charge longer. This effect of the ink has been discussed from various view points and can be explained by the theories of Böning and Grüner mentioned earlier.

\section{MEASUREMENTS AT THE PAPER GUIDE ROLLERS OF COMMERCIAL ROTARY PHOTOGRAVURES}

In these measurements, designed to investigate the influence of paper guide rollers on the electrostatic charge, two measuring heads were used. From measurements made on the web side which touches the metal of the guide roller it was found that fluctuations in the charge on plain paper webs are essentially completely evened out, whereas in printed paper webs this is only partially the case. The paper is partially discharged.

The charged paper is partially discharged upon coming in contact with the paper guide rollers and is recharged upon separation therefrom. Charge formations before and after the guide rollers are completely independent of one another. At high web speeds the charge can no longer flow completely from the web. There is only a smoothing out effect. Web speed influences all measurements, with increasing speed, the degree of smoothing out decreases. The charge formed during separation of the paper web from a guide roller is added to the charge already present on the web. In addition, the charge 
time than vice versa, i.e. the paper has the smaller area undergoing friction and must, hence, become negatively charged.

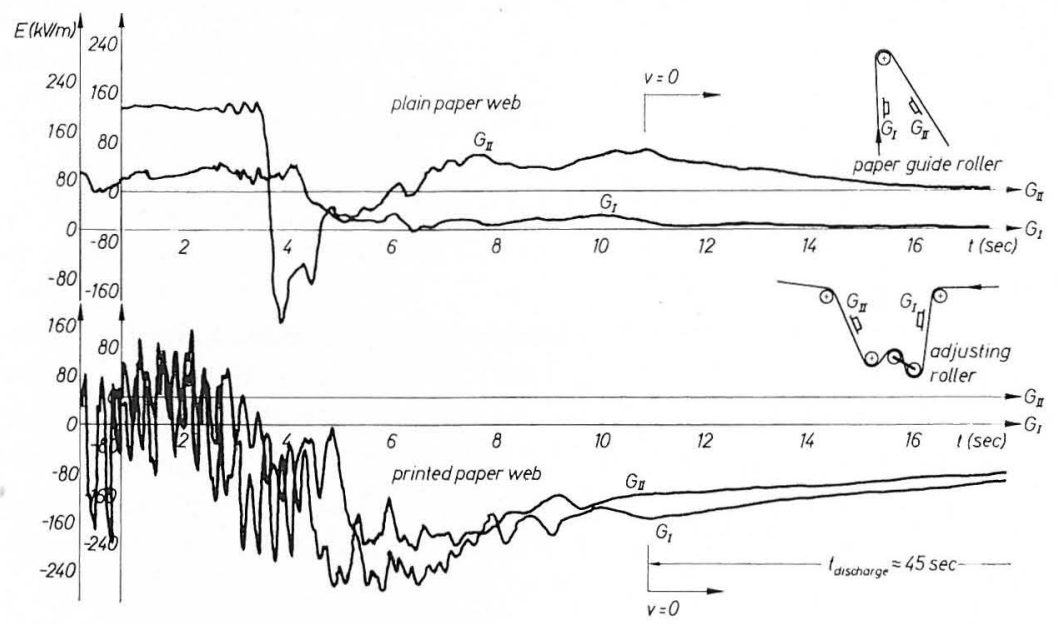

Fig. 7. The electrostatic characteristic of a paper web during cut off on a production rotary photogravure.

Both positive and negative charges were observed on printed paper webs. In this case, the ink which is rubbed off by the guide roller plays a role, in that it changes surface conditions among other things.

Measurements made with two measuring heads on the opposite side of the web from the guide roller hardly affected the charge on a plain paper.

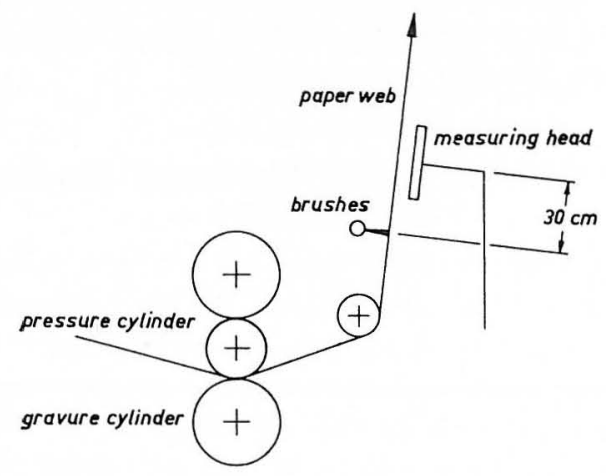

Fig. 8. Schematic diagram of the measuring apparatus for determining the influence of the brushes. 
In contact, a slight smoothing out could be observed on printed papers which generally carry a higher charge. Here, the charge is the source of an electric field that penetrates the back of the paper and affects the measurement. On a large rotogravure printing press in another printing plant, the influence of the brushes after the first verso printing unit (yellow) was measured (Fig. 8). At a machine speed of $v_{\mathrm{cyl}}=8000$ r.p.h., the average value of the charge on the reverse printing side, without brushes, was $-270 \mathrm{kV} / \mathrm{m}$. With the brushes in position, the charge sank to $-110 \mathrm{kV} / \mathrm{m}$. From this, we can see that the charge on the first and reverse printing sides of a paper web influence one another.

In summarizing the investigations made on paper guide rollers, mention hould be made that in addition to an increase in the average value of the harge with increasing machine speed, there is also an increase in the amplitude of the fluctuations themselves (Fig. 9). From the figures we see that the

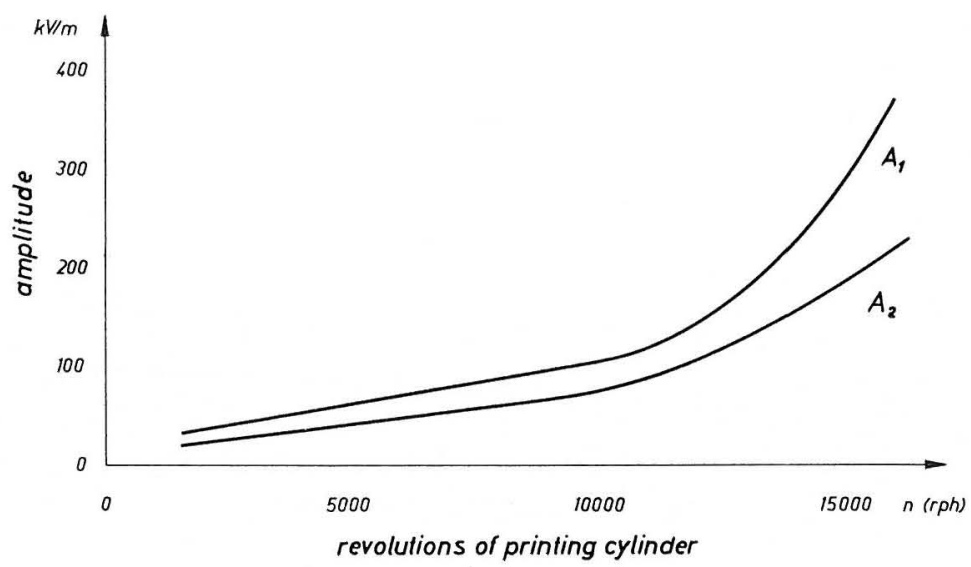

Fig. 9. Dependence of the amplitude of electrostatic charge fluctuation on the gravure cylinder r.p.h.

charge increases linearly until about $v_{\text {cyl }}=10,000$ r.p.h. and then at an ever increasing rate. These fluctuations of charge are by no means simple oscillations. They are the resultants of a number of superimposed oscillations of different frequencies, all of which are functions of the revolution rate. To date, the amount and distribution of ink and fluctuations in the tension of a paper web have been established as causes for these fluctuations in charge. There is no doubt, however, that climatic factors arising from draughts, drying cylinder, etc., affect the charge. 


\section{MEASUREMENTS ON THE PRINTING UNITS OF DIFFERENT-SIZED ROTARY PHOTOGRAVURE}

Before showing a survey of the charges measured at the various printing units of three commercial printing presses, it is worth remarking on the general trends.

The values measured after the printing units show different charge characteristics depending on the tonal value and the amount of ink used. This is supported by the fluctuations in charge which vary across the breadth of the web, as already shown.

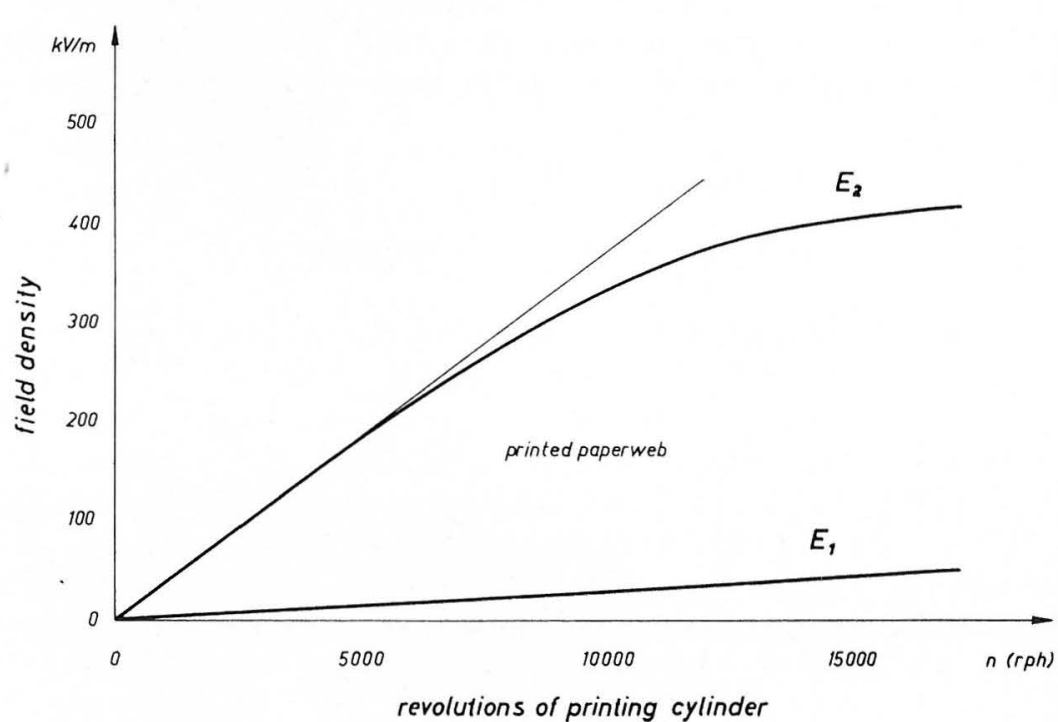

Fig. 10. The influence of an operating printing unit on charge development on an already printed paper web.

The charge increases exponentially with increasing web speed (Fig. 10).

Investigations to determine the influence of the heating effect of the drying cylinder showed that in a commercial printing press the charge decreased with increasing temperature both before and after the heating zone. Even small charges of approx. $200 \mathrm{kV} / \mathrm{m}$ drop to $35-40$ per cent of the value measured before the drying cylinder. The charge directly before the drying section fell some 3-5 per cent. At present nothing definite can be said either about the temperature of the drying cylinder or the aluminium guide rollers in the drying unit, 
Likewise, no definite statement can be made regarding the effect of the couch roll pressure on a commercial printing press. Figures 11 and 12 show that increasing the couch roll pressure can lead to either a positive or negative charge. No definite trend can be seen in the charges measured at printing units 11,12 and 13 . For a complete understanding, it is essential to determine the influence exerted by each of the inks used.

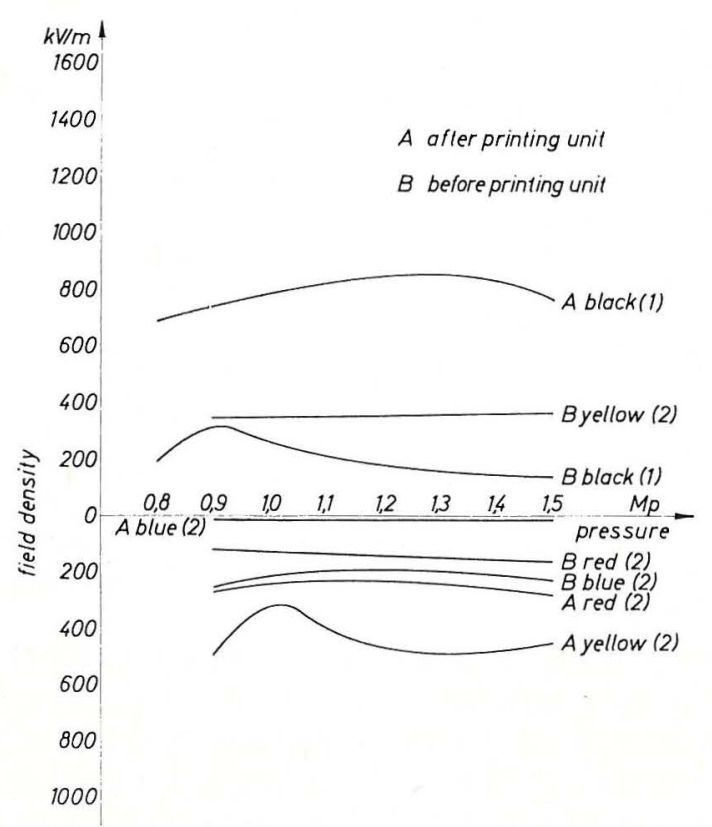

Fig. 11. Dependence of the electrostatic charge development on the printing pressure before and after printing units.

In other experiments carried out at the Darmstadt Institute it was found that the electrostatic charge build-up has a considerable effect on ink transfer during the printing process. These results were obtained with the aid of high-speed cine-photography.

A suitable apparatus capable of measuring the electrostatic charge arising from the contact between couch roll-ink (first print)-paper-printing inkgravure cylinder without weakening the electrostatic field being measured has already been constructed and tested and is at present being improved. At present, runs are being made at the Darmstadt Institute on a small, laboratory-scale photogravure using couch rolls made of a number of different conducting, semi-conducting and non-conducting materials. 


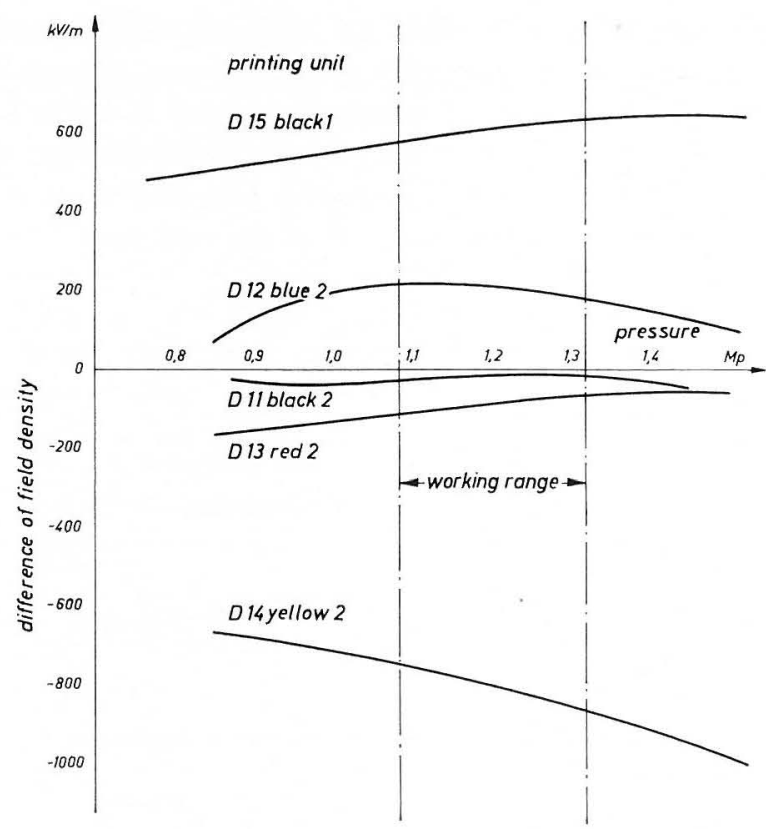

Fig. 12. The influence of printing pressure and printing ink on the charge development (measured on a large commercial rotary photogravure).

Figures 13 and 14 show the electrostatic charges measured at the various printing units of three large commercial rotary photogravures. In Fig. 13 we see the extreme values of $+1300,+1200$ and $+1450 \mathrm{kV} / \mathrm{m}$ were measured after the first printing unit (black). The second paper web carries a charge of $350 \mathrm{kV} / \mathrm{m}$ before entering the first printing unit (black), it picks up a charge of $850 \mathrm{kV} / \mathrm{m}$ and leaves the first printing unit with a charge of $+1200 \mathrm{kV} / \mathrm{m}$, and after the drying unit reaches a charge of $+1450 \mathrm{kV} / \mathrm{m}$. In the first verso printing unit the paper web undergoes an enormous discharge of -2430 $\mathrm{kV} / \mathrm{m}$ and leaves the unit with a charge of $-980 \mathrm{kV} / \mathrm{m}$. With $-2430 \mathrm{kV} / \mathrm{m}$ an extremely high field density charge was reached. All the field densities measured lay much lower than the dielectric breakdown strength of the air. The dielectric breakdown strength $\left(u_{d}\right)$ air is defined as:

$$
u_{d}=f(\delta . a)=f(p \cdot a)
$$

where: $\delta=$ relative air density,

$a=$ gap between plates,

$p=$ air pressure (atm).

At $p=1$ atm; $t=20^{\circ} \mathrm{C} ; a=1 \mathrm{~cm}$, the dielectric breakdown strength of air, $u_{d}$, is $\approx 32 \mathrm{kV}$. 


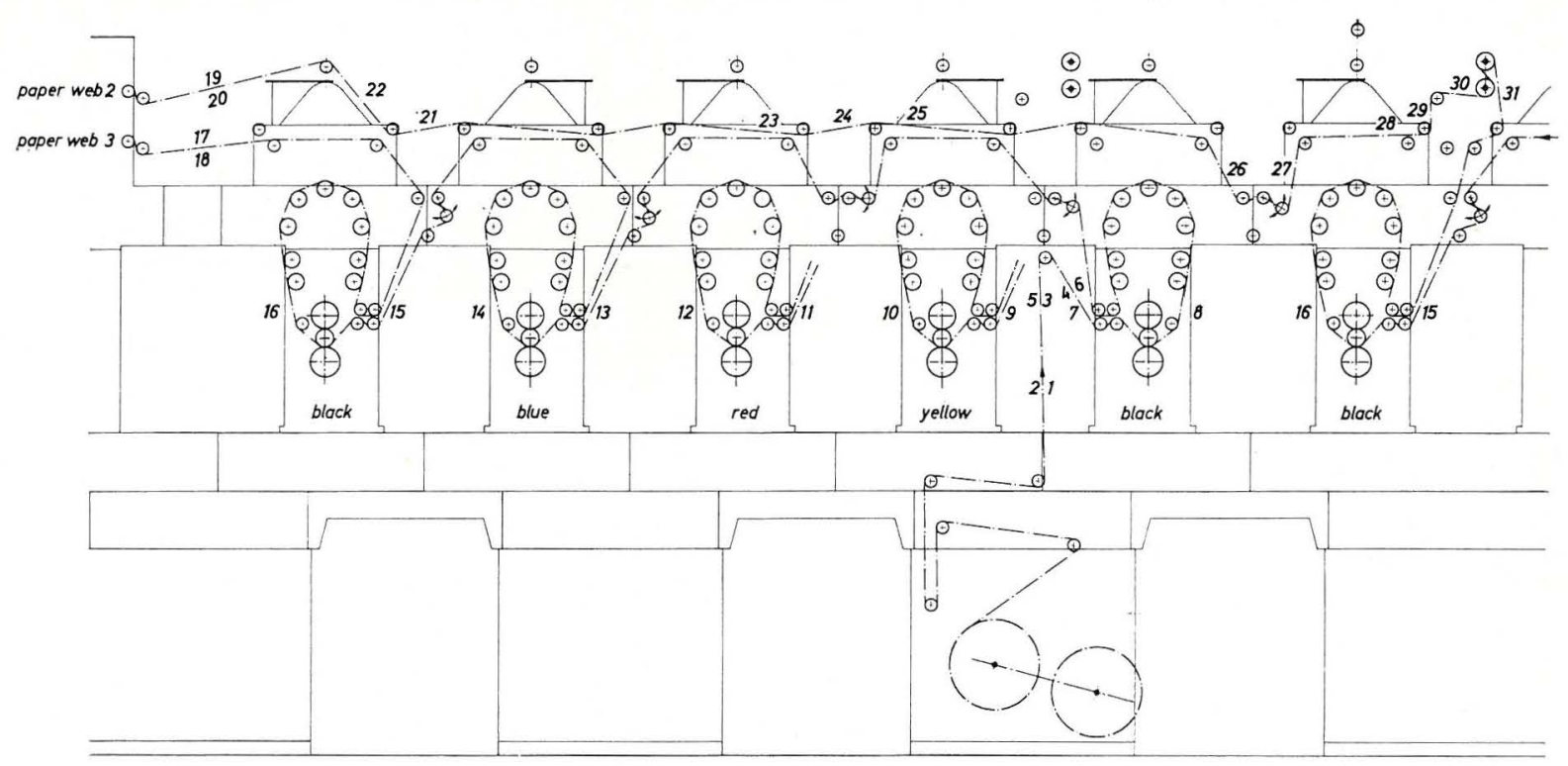

field density $\mathrm{kV} / \mathrm{m}$

\begin{tabular}{|c|c|c|c|c|c|c|c|c|c|c|c|c|c|c|c|}
\hline \multirow{3}{*}{ web } & & & & & & & & & & & & & & & \\
\hline & 1 & 120 & 133 & 220 & 260 & 120 & 128 & 490 & 1300 & 100 & -525 & -385 & -590 & -332 & -760 \\
\hline & 2 & - & - & - & - & - & - & 350 & 1200 & 1450 & $=980$ & -300 & -332 & -360 & -280 \\
\hline & 3 & - & - & - & - & - & - & 28 & -210 & - & - & - & - & -100 & -245 \\
\hline & & 1 & 2 & 3 & 4 & 5 & 6 & 7 & 8 & 9 & 10 & 11 & 12 & 13 & 14 \\
\hline
\end{tabular}

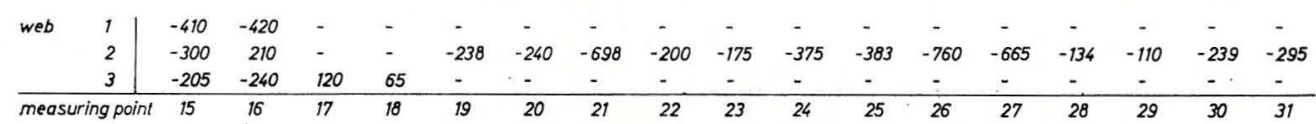

Fig. 13. Partial view of machine 5 listing the values measured at the various printing units. Scale $1: 25$. 


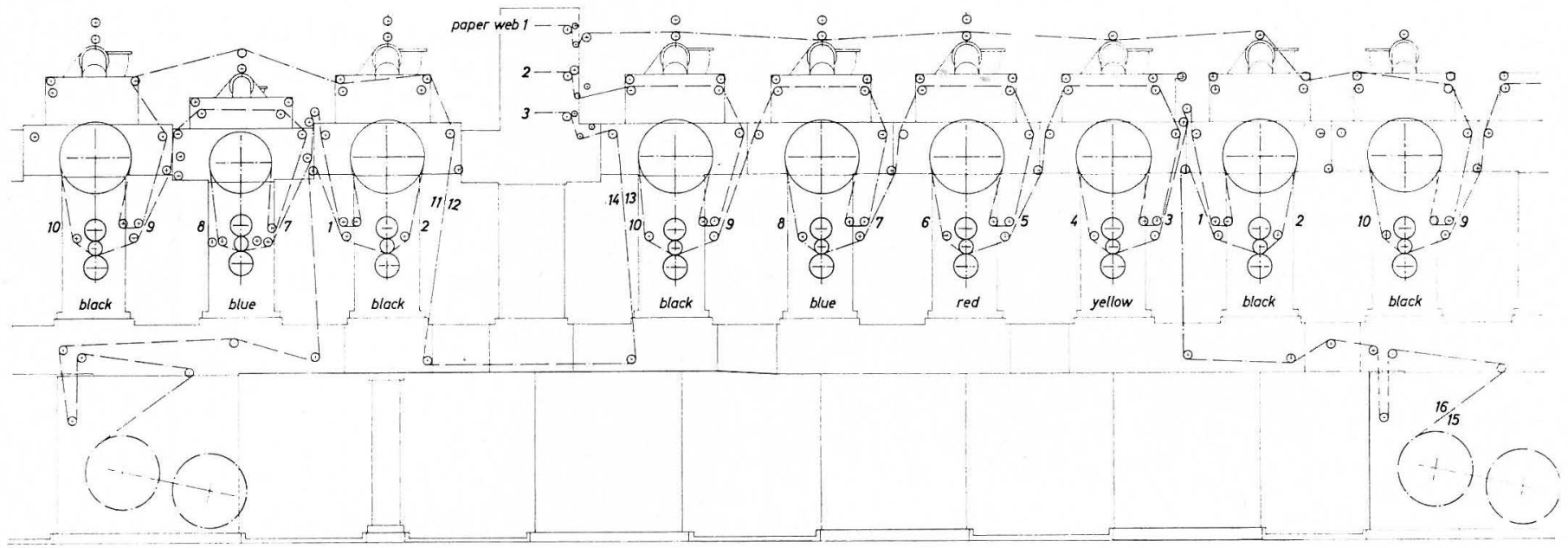

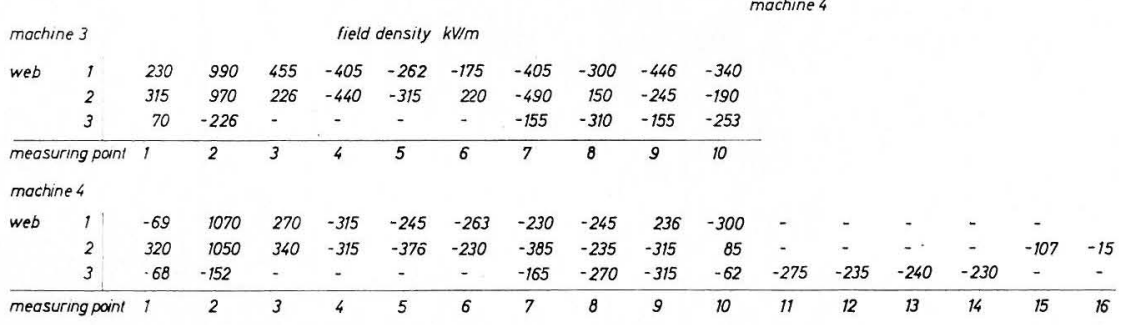

Fig. 14. Partial view of machines 3 and 4 listing the values measured at the various printing units. Scale 1:25. 
It is interesting to note that Reuter ${ }^{(5)}$ found the highest electrostatic charge (up to $+1750 \mathrm{kV} / \mathrm{m}$ ) after the verso printing unit of a rotary letterpress. At first glance, the negative charge on the third paper web after the first printing unit (black) seems surprising. However, paper webs 1 and 3 showed a similar increase in their negative charge between measuring points 15 and 16. In Fig. 14 similar trends are evident. The highest measured difference in charge $(+1140 \mathrm{kV} / \mathrm{m})$ occurred in the first printing unit (black) of press 4 . The relatively high drop in charge from positive to negative in the verso printing unit (yellow) of press 3 (approx. -860 , resp. $-666 \mathrm{kV} / \mathrm{m}$ ) and in press 4 (approx. -585 , resp. $-655 \mathrm{kV} / \mathrm{m}$ ) may be regarded as typical.

Measurements at the printing units of commercial printing presses clearly indicated that owing to the large number of parameters involved, any statement would need to be of a more or less complex nature. For this reason measurements were simultaneously carried out on a small experimental photogravure printing press as well as on four different types of commercial printing presses.

\section{SUMMARY}

Experimental results from large commercial rotary photogravures are discussed. First, the mechanism of electrostatic charge development and the applicable physical laws are reviewed. Contact and friction between paper web and paper or other materials are regarded as the primary causes of the formation of an electrostatic charge on the paper web.

Questions relating to the removal of the charge through the use of dischargers or of increasing the conductivity of a paper by chemical means either during paper production or subsequent surface treatment have not been considered.

The charge development on the two sides of the paperweb may be different or influence one another. The decay of charge is exponential with time where $T_{\text {printed }}>T_{\text {plain }}$.

The influence of the amount and distribution of ink on the charge is discussed. Printing speed, printing pressure and temperature (room, drying section and press) greatly affect the charge development.

High-speed photography showed that ink transfer was greatly affected by the electrostatic charge.

The mechanism of electrostatic charge development in the printing units is very complex owing to the different materials involved.

\section{REFERENCES}

1. V. Macourek, Neutralizátory statické elektriny (Dischargers). Rosvoj techniky v polygrafii, Praha (1964) No. 3.

2. Hochhauz, Mit Russ gefüllte Papiere. Zellstoff u. Papier (1961) No. 9. 
3. Elektrisch leitendes Papier. DBP 1134579 v. 14.2, 1963.

4. M. HAYEK, Elektrisch leitendes und aufladungsfreies Papier. TAPPI (Feb. 1960) 432.

5. Electrically conductive paper for non impact printing, TAPPI (Dec. 1964) 4712.

6. H. GRÜNER, Untersuchungen über den Entstehungsmechanismus der elektrostatischen Aufladung von Faserstoffen. Dissertation T. H. Darmstadt (1953).

7. A. CoHn and A. Curs, Studien zur Berührungselektrizität. Z.f. Physik, Bd. 29 (1924).

8. F. SснміDT, Über elektrische Ladungserscheinungen an Papieren. Dissertation T. H. Darmstadt (1937).

9. W. Wegener and D. Quambusch, Zusammenhang zwischen Raumklima und der elektrostatischen Aufladung des Spinnmaterials. Veröff. No. 897, T. H. Aachen (1960).

10. P. BöNING 1. Die Rückspannung. 2. Zur Theorie des Ionendurchschlages fester Isolierstoffe. Woosung (1933).

11. P. BöNING, Ionenbewegung. Woosung (1935).

12. P. BöNING. Elektrische Isolierstoffe. Vieweg (1938) Braunschweig.

13. E. Flegler. Electrostatic charges on printed paper webs. GRI-Newsletter, Feb. 1965.

14. H. F. Schwenkhagen, Elektrostatische Aufladungen und ihre Beseitigung. MelliandTextilber. (1953).

15. K. Reuter, Bemerkungen zur elektrostatischen Aufladung an Druckmaschinen. Papier und Druck (1960).

\section{DISCUSSION}

HUNDERUP-JenSEN: We occasionally experience static in high speed rotary letterpress work. It occurs on the roll stand where there are brake belts on the outer surface of the reel. The static appears in a strip along the sheet and attracts loose fibre that is then transported to the printing region of the press and causes filling in. We found that metal brake bands generated more static than rubber ones.

MARVIN C. Rogers: Signatures or folded books from the folders on letterpress and rotogravure presses always show difficulty in opening when the paper is dry (low moisture). This indicates that negative and positive electrical charges must be present on the same side of the paper.

(1) Examination of many books from gravure and letterpresses by use of a powder mixture containing sulfur and lycopodium powders showed an unpredictable random distribution of positive and negative charges over the paper surfaces. In letterpress these charges tended to follow the outlines of the printed images. We cannot assume that the generated electrostatic charge is predominantly negative or positive. Both charges are found.

(2) The press is at ground or null potential. In generating a charge on paper then an opposite charge is generated on the press and immediately conducted to ground. Therefore the observer will find high alternating potentials.

(3) Dry paper is a dielectric and may easily hold a variety of charges at potentials low enough to prohibit their neutralization without assistance of electrical conductors.

An air-water spray will effectively neutralize static electrical charge on most papersif time is allowed for diffusion of water through the air layer over the paper and into the paper itself.

The use of a "brush", i.e. many finely pointed metal threads, in close proximity to the paper will also effectively reduce the charge.

(4) Experience confirms that a charge develops each time there is contact between a dielectric material (paper) and another surface-e.g. parts of the press.

FrITSCH: Thank you for your detailed comment. On printed paper I observed that there was as in your case with the printed picture a "charge-picture". In my paper I showed that I measured the time of discharge and that this, for a printed paperweb, is much higher than for a plain paperweb $\left(T_{\text {printed }}=7.0 \times 10^{-12}+9.0 \times 10^{-12} . T_{\text {plain }}\right)$. 
The conductivity of inks is about $10^{-9}$ and of uncoated papers between $10^{-5}$ and $10^{-8}$ (1/ohm.cm).

I believe that conductivities between $10^{-5}$ and $10^{-12}$ set a limit to electrification. BANKS: We also confirm the observation by Dr. Rogers that a charged surface really consists of mixed patches (mosaic) of positive and negative charges but with one kind predominating in general. 